\title{
The Case of Sharon Considered from the Vantage Point of Interpersonal Defense Theory
}

\author{
MICHAEL A. WESTERMAN ${ }^{a, b, c}$
}

\author{
${ }^{a}$ New York University \\ ${ }^{\mathrm{b}}$ Correspondence regarding this article should be sent to: Michael A. Westerman, Department of Psychology, New \\ York University, 6 Washington Place, Fourth Floor, New York, NY 10003, USA. \\ Email: michael.westerman@nyu.edu \\ ${ }^{\mathrm{c}}$ The author is grateful to the Brief Psychotherapy Research Project (J. Christopher Muran, Principal Investigator) \\ at Mount Sinai Beth Israel Medical Center, New York, for making available material on the case reported on in this \\ set of articles.
}

\begin{abstract}
As part of this project comparing analyses of the case of Sharon based on Interpersonal Defense Theory (e.g., Westerman, 2018, 2019) and Interpersonal Reconstructive Therapy (e.g., Benjamin \& Critchfield, 2010), this paper considers the case from the vantage point of Interpersonal Defense Theory. The first half of the paper presents the theory's novel approach to case formulation. It begins by explaining the kind of case formulations the Interpersonal Defense Theory calls for in general and then presents a formulation of Sharon's case based on the theory, illustrating that formulation with an examination of a transcript of a session excerpt from her therapy. The second half of the paper discusses the theory's implications for treatment, beginning with a presentation of its treatment implications in general and then turning to its specific implications for Sharon's case. Overall, the paper shows that the theory sheds new light on how to understand Sharon's problems, provides a possible explanation for why the treatment, which was based on Brief Adaptive Psychotherapy (Pollack, Flegenheimer, Kaufman, \& Sadow, 1992), resulted in a poor outcome, and suggests a different therapeutic approach that might have been more successful.
\end{abstract}

Keywords: Interpersonal Defense Theory; coordination; case formulation; process models; therapy relationship processes; insight-oriented interventions

The previous paper in this set of articles presented basic information about the case of Sharon, a 28-year-old female patient who entered therapy because she was having a great deal of difficult getting over a broken engagement, an engagement she had ended. In this paper, I employ Interpersonal Defense Theory (e.g., Westerman, 2018, 2019) to consider Sharon's therapy as part of a project that uses this case to compare Interpersonal Defense Theory and Interpersonal Reconstructive Therapy (IRT; e.g., Benjamin \& Critchfield, 2010). I begin by explaining the novel approach to case formulation that Interpersonal Defense Theory offers. I then offer a formulation of Sharon's case based on the theory and illustrate that formulation by analyzing the transcript of a segment of a session from Sharon's therapy. In the second part of the paper, I first discuss in general terms the implications of Interpersonal Defense Theory for 
effective therapeutic work and then employ those ideas to consider the therapist's part in the transcribed segment and in Sharon's therapy overall.

\section{CASE FORMULATION}

\section{Basic Approach to Case Formulation}

Case formulations are theory driven (Eells, 2007; Kramer, 2019; Persons, 1991). Hence, the first step in explaining Interpersonal Defense Theory's approach to formulation is presenting the theory's main ideas.

\section{Interpersonal Defense Theory}

Interpersonal Defense Theory is an interpersonal conceptualization of defense processes. As in psychoanalytic theory, Interpersonal Defense Theory focuses on conflicts between wishes and fears. However, whereas psychoanalytic theory views defenses as intrapsychic processes (the ego mechanisms of defense) that modulate internal experiences of anxiety, guilt, and selfesteem, Interpersonal Defense Theory treats defenses primarily as interpersonal action patterns that attempt to influence what transpires in relationships. One key tenet of the theory is that people employ interpersonal defenses to negotiate conflicts between interpersonal wishes and fears, specifically, conflicts in which pursuing a wished-for kind of relationship opens up the possibility that the other person might respond in a particular way the individual dreads. (For summaries of research supporting this tenet of the theory and the other tenets presented below, see Westerman (2018, p.316; 2019, pp. 329-331.)

Defensive interpersonal patterns are attempts by individuals to pursue their wish while also avoiding their fear, even though pursuing the wish opens up the possibility of the feared interpersonal outcome. Parts of defensive patterns pursue the wished-for kind of relationship while other parts attempt to "cancel out" how doing so opens up the possibility that the relationship will proceed in the way the person fears. As a result, these patterns are characterized by recurring breaches of coordination, that is, the person's contributions to interactions fail to mesh with the other person's bids and with the first person's own prior bids, and this happens again and again. When we turn to Sharon's case, I will illustrate this idea about recurring failures of coordination as well as the other phenomena identified by Interpersonal Defense Theory that I present here.

Although interpersonal defenses attempt to make it possible to realize the wish and also avoid the fear, they actually affect what transpires in relationships in a complicated way that differs in important respects from what the person is trying to make happen. I call the actual outcomes of defensive interpersonal action patterns their feed-forward effects.

According to the theory's tenets about feed-forward effects, interpersonal defenses succeed at avoiding feared outcomes. Note that this tenet differs from the concept of the selffulfilling prophecy (e.g., Downey, Freitas, Michaelis, \& Khouri, 1998; Wachtel, 2017). Other tenets about feed-forward effects, however, make it clear that, ultimately, defensive patterns do not "work." They actually make it very unlikely that wished-for relationship outcomes will be realized, even though they include repeated attempts at pursuing the wish. In addition, they 
promote certain negative outcomes that are distinct from the person's central interpersonal fear. One other tenet about feed-forward effects maintains that an individual's interpersonal defenses will promote specific positive outcomes, but those outcomes are distinct from the wish.

Wachtel (2017, pp. 519-520, italics in original) made a very important point when he said, "in order to help the person generate change in his or her life, we need to understand with great clarity how he or she keeps it the same." Interpersonal Defense Theory offers an account of why people persist in engaging in defensive interpersonal patterns. According to the theory, the likely responses to defensive behavior function to maintain those patterns because: (1) the other person does not behave in the feared manner, even though the first person pursues his or her wish (albeit in a defensive way), (2) the positive responses distinct from the first person's wish support his or her continuation of the defensive pattern, (3) the first person can continue to try to pursue the wish by acting defensively, even though the pattern does not actually lead to realizing the wish, and (4) although interpersonal defenses promote negative outcomes distinct from the fear, those relationship events are less salient for the first person than his or her central fear.

Clinical Relevance. These ideas about interpersonal processes have clear significance for clinical concerns. Most notably, in many cases, patients' presenting problems simply are about relationship difficulties. Moreover, difficulties in interpersonal relationships often play a key role when that may be less obvious, for example, when a college student is struggling with "test anxiety" that is actually linked to unresolved, longstanding problems in the student's relationships with his or her parents related to their expectations about achievement.

Interpersonal Defense Theory also is very relevant for matters of clinical importance because the interpersonal phenomena it considers occur in the therapy context as well as in other parts of a patient's life. The theory offers a new way of conceptualizing transference and countertransference phenomena. It calls for viewing transference as the appearance of a patient's defensive, noncoordinating pattern in his or her relationship with the therapist and countertransference as the appearance in the therapist's behavior of the feed-forward effects of the patient's defensive pattern. Here, I should note that although patients' interpersonal defenses "pull" for countertransferential responses (conceptualized as the feed-forward effects of those defensive patterns), it is not necessarily the case that a therapist will respond in that manner.

In addition, Interpersonal Defense Theory has relevance for clinical issues when it comes to patients' symptoms. According to the theory, symptoms are linked to interpersonal defenses in two ways. One point here is that it is often the case that symptoms such as aggression or being withdrawn are parts of defensive interpersonal patterns that play roles in a patient's attempts to negotiate conflicts between his or her central interpersonal wish and fear. Another point is that symptoms such as anxiety and other problematic emotions like shame frequently are consequences of dysfunctional defensive interpersonal patterns. Furthermore, these "outcomes" often also play roles maintaining defensive patterns.

\section{What Case Formulations Based on the Theory are Like}

Case formulations based on Interpersonal Defense Theory offer idiographic conceptualizations of cases that are comprised of the following components: (1) The patient's central wished-for kind of interpersonal relationship, which includes the patient's part in the 
wished-for type of exchanges as well as the other person's response, (2) the patient's central feared kind of relationship, which includes the patient's part in the feared type of interpersonal exchanges and the other person's response, (3) the particular noncoordinating pattern that characterizes the patient's interpersonal defenses, (4) particular negative responses distinct from the patient's fear that his or her defensive action patterns often lead to, and (5) particular positive responses distinct from the patient's wish that his or her defensive action patterns often promote.

Note that Interpersonal Defense Theory and its case formulations provide process models of interpersonal phenomena. The components of case formulations identify key features of a case, but those features are parts of accounts of how interpersonal behaviors are organized over time. This includes the basic idea of defensive coordination failures and the tenets about causal processes that tie certain phenomena together (i.e., how noncoordinating defensive patterns promote feed-forward effects and how those effects function to maintain the pattern). Hence, the theory and its formulations of cases provide explanatory models that help us understand problematic processes and that have implications for treatment. I illustrate these points in several places later in the paper.

The Structural Analysis of Social Behavior (SASB; e.g., 1979) provides a very useful model for conceptualizing the parts of case formulations based on Interpersonal Defense Theory. There are several reasons why the SASB model is well-suited for this purpose.

Figure 1 presents the two "Interpersonal" foci of the SASB full model, which was introduced in the previous paper in this set of articles. One useful feature of this part of the SASB full model is that it directs attention to interpersonal outcomes, which are key parts of a case formulation based on Interpersonal Defense Theory. According to the theory, such inner experiences as feelings of anxiety and feeling inadequate are important outcomes to consider, but the primary focus should be on outcomes regarding how others respond to the patient when the patient behaves a certain way.

Specifically, the points in Figure 1 provide a systematic vocabulary of possible ways a significant other could conceivably respond to a patient. For example, in a particular case, the wished-for outcome could be point 142, "provide for, nurture," and the feared outcome could be point 136, "put down, act superior." Similarly, the points in Figure 1 provide a vocabulary of possible responses by a significant other that might be the type of positive response distinct from the wish that a patient's noncoordinating, defensive pattern often promotes or the type of negative response distinct from the fear that the patient's pattern promotes. For example, in the hypothetical case we were just considering, the positive response distinct from the wished-for outcome that the patient often encounters might be point 117, "you can do it fine," and the negative response distinct from the feared outcome might be point 123, "abandon, leave in lurch."

Another feature of the SASB full model that makes it very useful for arriving at case formulations is that it presents a highly differentiated conceptual space of interpersonal behaviors. Although all points on the right sides of the two foci are positive in affiliation and all points on the left sides are negative in affiliation, the points on a given side of the model differ from each other in degree of affiliation. Moreover, different points on the same side differ in degree of interdependence, and in some cases, they differ a great deal on that dimension. This 
makes it possible to recognize that a patient with a central wished-for outcome of "confirm as ok as is" (point 113), but to whom others typically respond with "encourage separate identity" (point 118) is encountering responses that are positive but distinct from his or her wish. Similarly, if the central feared outcome for a particular patient is "angry dismiss reject" (point 121 ) and others frequently respond to the patient with "neglect interests, needs" (point 125), it is true that this patient encounters many negative responses, but those responses are distinct from his or her central fear.

As was discussed in the prior paper in this set of articles, there are theoretical principles associated with SASB (Benjamin, 1979; 1987). Interpersonal Defense Theory incorporates one of those principles in how it conceptualizes the patient's part in his or her wished-for kind of interpersonal relationship. According to the principle of complementarity, two behaviors "pull" for one another if they are identical on both the affiliation and interdependence dimension but different in that the focus of one is Other and the focus of the other behavior is Self. For example, if person A behaves in the manner indicated on Figure 1 by point 146, "pamper, overindulge" on the Other focus, that will make it more likely, although not necessarily the case, that person B will behave in the manner described by point 246 , "cling depend," on the Self surface, and vice versa.

According to Interpersonal Defense Theory, a person's part in his or her wished-for kind of relationship and that person's wished-for response are complements. If we return to the hypothetical example in which a particular individual's wished-for response is "provide for, nurture" (point 142), that individual's part in his or her wished-for relationship will be "accept caretaking" (point 242). Also, according to the theory, a person's part in his or her feared kind of relationship will be the same as his or her part in the wished-for outcome. For example, the central fear for the hypothetical person we were just considering will be that some response that the person dreads might occur if he or she "accepts caretaking." According to Interpersonal Defense Theory, the feared outcome for this particular person could be any one of the behaviors on the left side of the Other circumplex depending on that person's early childhood experiences. I will offer further comments about these parts of the theory shortly.

There is one more way in which SASB enters into case formulations based on Interpersonal Defense Theory. This other way concerns how to recognize and accurately characterize an individual's defensive noncoordinating pattern. I will also return to this point shortly.

\section{Procedure for Arriving at a Formulation}

The way a therapist or researcher goes about arriving at a case formulation for a given case based on the ideas I have presented so far is mostly guided by a careful examination of the patient's interpersonal interactions. In particular, patient-therapist exchange is the main source of data used. The therapist or researcher considers whether the patient's contributions to the exchange coordinate, or mesh, with the therapist's contributions and the patient's own prior contributions and whether there is a recurring pattern in whatever coordination breaches occur. If there is a recurring pattern of breaches, the therapist or researcher tries to determine whether parts of the pattern when considered by themselves are repeated attempts to pursue a desired interpersonal outcome. This is done using the SASB model and the principle of 
complementarity. Going back to one of our hypothetical examples, if parts of the patient's pattern are recurring bids in which the patient "accepts caretaking" (point 242), then those aspects of the patient's pattern are taken to be efforts to pursue the wished-for response of "provide for, nurture" (point 142). The feared outcome is taken to be the kind of response (conceptualized in SASB terms) that the patient attempts to avoid with the other part of his or her pattern that does not mesh with the part that pursues the wish.

This is a complex, iterative process that involves carefully examining patient-therapist interactions in a number of sessions while making and then revising provisional formulations of the patient's noncoordinating, defensive pattern, the patient's part of the central wish and the wished-for response, and the patient's part in the central fear (which, again, will be the same as the patient's part in his or her wish) and feared response.

This process is supplemented by considering the patient's narratives about other contemporaneous relationships and his or her past relationships since childhood. These considerations are given less weight because people's narratives of relationship events only rarely include the kind of detail necessary regarding how their own behavior is organized over time. On those occasions when they do, however, it is very helpful to determine whether the pattern described in the narrative agrees with tentative formulations based on in-session interactions.

Another important part of the procedures for arriving at a case formulation involves patients' narratives about their childhood relationship experiences. According to Interpersonal Defense Theory, wish-fear conflicts and interpersonal defenses develop as the result of repeated early experiences in which a child pursued an interpersonal outcome he or she especially desired in a straightforward, nondefensive manner and significant others responded in a particular negative way. How the child behaved in those situations becomes the person's part in the central wished-for kind of relationship, and the response he or she was hoping for becomes the wishedfor outcome. How the child behaved in those early situations also becomes his or her part in the central feared kind of relationship, and the negative response the child actually repeatedly encountered becomes the key feared outcome. Early childhood narratives are helpful because the patient's part of the wish and the feared outcome often appear especially clearly in them.

One more step in the process of arriving at a case formulation involves identifying the positive responses distinct from the wished-for outcome and the negative responses distinct from the feared outcome that the patient frequently encounters. This step is accomplished by examining how the therapist responds to the patient in sessions and by considering the patient's narratives about how significant others in the patient's life have often responded to the patient since after childhood.

\section{The Formulation for Sharon's Case}

Turning to Sharon's case, I arrived at a formulation following the procedures described above. I will have a good deal to say about how examination of Sharon's interactions with the therapist supported my formulation at a later point when I consider the transcript of part of a session from her therapy. At this point, I will comment on some historical data obtained from her responses on questionnaires and her narratives in sessions about her childhood. In that material, 
Sharon reported that she was happiest when she was acting on her own accord in ways she saw fit, which she referred to as being "free" or a "free spirit." However, she also voiced concerns that she would end up being left alone if she behaved that way. Her remarks about her childhood indicated that acting as a free spirit would be met by a lack of involvement by her mother, whom Sharon saw as vain and self-absorbed. Also, although Sharon's father was actively involved with her, Sharon felt that he would turn away from her if their involvement was not on his terms.

According to the formulation I arrived at based on this historical data and careful consideration of Sharon's interactions with the therapist, Sharon's wish was that when she acted independently and took stands (in SASB terms: 218, "own identity and standards;" 217, "assert on own;" 216, "put cards on table"), which was Sharon's part in her wished-for kind of relationship, others would affirm her and show appreciation for her independence and viewpoints (118, "encourage separate identity;" 117, "you can do it fine;" 116 , "carefully fairly consider"), which was her wished-for response. Her fear was that when she pursued her wish by acting independently and taking stands (once again, 218, "own identity and standards;" 217, "assert on own;" 216, "put cards on table"), which was her part in her feared kind of relationship as well as her wished-for kind of relationship, others would act in ways that showed they were uninterested in her and stay uninvolved with her (126, "ignore her, pretend she is not there;" 125 , "neglect her interests and needs"), which was her feared response.

With regard to the third component of the formulation, I arrived at the following description of the noncoordinating, defensive pattern that characterized much of Sharon's interpersonal behavior: Sharon related to her therapist and also significant others in a manner in which she persistently, stubbornly pressed on with her point of view and tried to get interactions to proceed along the lines she wanted to pursue, while she also repeatedly appeared to agree with and defer to the other person. In fact, she was not really responsive but, rather, she actually was intransigent in her persistence. She provoked and baited her therapist and other people by appearing to go along and then repeatedly moving away from going along to shift back to pressing on with her point of view. In addition, she did not clearly present where she stood.

In keeping with the tenets of Interpersonal Defense Theory about feed-forward effects and for reasons I will explain later, Sharon's defensive, noncoordinating pattern actually worked against significant others responding to her in her wished-for or feared ways. Although others did not affirm her independent viewpoint (her wished for response), at times they behaved in ways that were positive in the sense that they acted in a benevolent managing manner (SASB $144,145,146,147,148)$, that is, in positive ways that were distinct from Sharon's wish. At other times, although others did not neglect Sharon and stay uninvolved (her feared response), they related to her in hostile controlling and angry, attacking ways (SASB 135, 136, 137, 138, and 130, 131). These were negative responses distinct from Sharon's fear.

\section{$\underline{\text { Using the Case Formulation to Understand Clinical Material }}$}

I now turn to a transcript of part of a session from Sharon's therapy to illustrate the formulation and to show how it helps us understand Sharon's problems. The transcribed segment begins about 10 minutes into session 11. In that session, Sharon attempted to get the therapist to give his opinion about a letter she received from her ex-fiancé Jeff after she sent him a ticket to a 
show that she hoped he would go to with her. The therapist did not want to offer his opinion, but rather tried to get Sharon to say what she thought about Jeff's letter.

Here is the transcript:

(1) Patient: and what do you think? (smiles)

(2) Therapist: Well I don't know if what I think is important because//

(3) Patient: //(interjects) it's important (laughs)

(4) Therapist: because you know him much better than I do//

(5) Patient: //(interrupts) Right, but no, it's an opinion I'm just curious//

(6) Therapist: //(interrupts) yeah, I really have no idea other than what you're telling me. You know what I mean...I think it's hard for you to make a decision

(7) Patient: um huh (yes)

(8) Therapist: for yourself...you know that you're um you know soliciting my opinion or your friend's opinion even though you know you really know him [patient nodding] much better than anybody else.

(9) Patient: True, but I think this just this is it's not definitive what it means so I am curious to see//

(10) Therapist: um huh (yes, backchannel)

(11) Patient: What other people are going to interpret as being...I mean, you're a man and if you wanted to hurt somebody umm (pause) would that be the choice of words you would use?

The exchange went on in a similar vein for about four minutes and then continued as follows:

(12) Therapist: ...so I'm wondering if//

(13) Patient: //(interjects) well

(14) Therapist: you like to be in a kind of confused state in order to avoid upsetting topics

(15) Patient: while by being confused I'm not putting an ending again to it

(16) Therapist: nods (backchannel)

(17) Patient: and definitely does serve a purpose.

(18) Therapist: Right.

(19) Patient: I guess it (pause) but he's (smiles) helping that along//

(20) Therapist: //(interrupts) So you don't have to feel pain.

(21) Patient: Right, but he's helping that along because he he has//

(22) Therapist: //(interrupts) maybe

(23) Patient: well//

(24) Therapist: //(interrupts) We're not here to analyze Jeff, we're here to look at you...

Explaining the Transcribed Exchange. Sharon's contributions to this exchange probably seem problematic to the reader. And no doubt, many therapists would think that they reflect 
some kind of problem. But how should we understand this example of her interpersonal behavior?

We should first consider how to characterize Sharon's part in the interaction. As a process model, Interpersonal Defense Theory calls for focusing on how interpersonal behaviors are organized over time. In particular, the theory's concept of coordination directs our attention to examining whether a patient's contributions to an exchange mesh with the therapist's bids and with the patient's own prior bids. If we consider the transcript along these lines, we see that Sharon's behavior in the excerpt was characterized by a recurring pattern of coordination failures. That pattern is a specific concrete example of the general description of her defensive, noncoordinating pattern that I presented earlier as part of the case formulation. In the transcribed segment, Sharon pressed on with trying to get the therapist to offer his thoughts about Jeff's letter while she also repeatedly moved away from doing that to apparently agree with bids by the therapist that pointed in very directions (first to Sharon's thoughts about the letter and later to why Sharon kept herself in a confused state) only to return again and again to trying to get the therapist to give his opinion about the letter.

If we examine the transcript closely, we can identify each of Sharon's recurring failures of coordination. In the first turn, Sharon asks the therapist for his opinion about Jeff's letter. In turn 2, the therapist begins to indicate that he does not think his opinion is important when Sharon interrupts him to declare "it's important" in turn 3. In turn 4, the therapist completes the bid he started to make in turn 2, explaining that Sharon knows Jeff better than he does. Sharon's contributions to the exchange in turns 5 and 7 are coordination breaches. She begins each of those turns by agreeing with the therapist's previous comment (she starts turn 5 agreeing that she knows Jeff better than the therapist does, and she starts turn 9 by agreeing with the therapist's suggestion that it is difficult for her to make decisions) and thereby shifts away from her own prior comments. In addition, in both cases after initially voicing agreement she continues as if she had not just assented to the therapist's points and returns to trying to get him to tell her his thoughts about the letter. Therefore, the second parts of turns 7 and 9 fail to mesh with what Sharon herself said in the initial parts of those turns and they fail to mesh with the therapist's bids in the prior turns. In turn 11, Sharon continues on from the end of what she began to say in turn 9 and ends turn 11 by posing a question embedded in which is the phrase "if you wanted to hurt somebody." Where did that idea come from? It is another coordination breach because it does not really fit without being introduced in some way.

In turns 12 and 14, the therapist builds on his previous point that it is difficult for Sharon to make decisions by suggesting that she likes being confused because it provides a way for her to avoid "upsetting topics." Sharon's noncoordinating pattern is even clearer in what follows because she not only apparently agrees with the therapist's viewpoint, she actually expands on it (turns 15 and 17), notwithstanding her own prior efforts to get the therapist to express his opinion about the letter. She then begins turn 19 in a manner that appears to be continuing along the same vein (i.e., building on the therapist's point), but after a pause she negates her own apparent agreement in turns 15 and 17 and the beginning of turn 19 and returns to her persistent (but erratic) focus on Jeff's letter, maintaining that there was something about it (not about her preference for remaining confused) that was making it hard for her to determine what to think about the letter. Turns 20 and 21 repeat this failure of coordination. In turn 20, the therapist 
suggests that if there was something about Jeff's letter that made it difficult to interpret, Sharon was making use of that to not "feel pain." Sharon appears to agree with this point at the beginning of turn 21, but then she returns to focusing on Jeff's letter rather than anything about herself in the remainder of the turn as if she had not just assented once again to the therapist's viewpoint.

Why did Sharon act this way? As I explained earlier, according to Interpersonal Defense Theory, recurring noncoordinating patterns are (ultimately unsuccessful) ways of negotiating conflicts between interpersonal wishes and fears. Coordination breaches occur because the patterns include repeated attempts by an individual to pursue his or her central wish and other parts of the pattern that are efforts to avoid feared interpersonal outcomes that pursuing the wish typically makes possible.

We can begin to consider Sharon's behavior from this vantage point by asking whether Sharon's pattern included repeated attempts to pursue her wish. According to the case formulation, Sharon could pursue her wished-for kind of relationship scenario by acting independently and taking stands. In fact, taken by itself (i.e., out of context), each of the following contributions to the exchange was an effort by Sharon to pursue her wish by taking a stand (SASB 217, assert on own): turn 3 ("it's [the therapist's view of the letter] important"), the second part of turn 5 ("no, it's [the therapist's view] an opinion"), second part of turn 9 ("it's [the letter] not definitive what it means"), second part of turn 19 ("he's helping that along"), and the second part of turn 21 ("he's helping that along because he has [bid was interrupted by therapist]"). If once again considered by itself, each of these turns might have led to Sharon's wished-for response of being affirmed and shown appreciation for her independent viewpoints.

Note that it was also the case that each of those bids, taken by itself opened up the possibility of Sharon's fear, that is, that the therapist might respond by neglecting or ignoring her and staying uninvolved when she took an independent stand. According to Interpersonal Defense Theory, however, defensive, noncoordinating patterns do not only include efforts to realize central interpersonal wishes, they also include parts that are attempts to "cancel out" the possibility that pursuing the wish will lead to interpersonal fears occurring.

Although Sharon repeatedly pursued her wish by taking a stand with each of a number of the individual bids she contributed to the exchange, she also derailed each of those bids by going on to apparently agree with and defer to the therapist's bids, even though his contributions expressed viewpoints that differed markedly from her own. Moreover, each of her contributions that was an attempt to pursue her wish failed to clarify or expand on her other bids of this kind that preceded it. As a result, notwithstanding Sharon's repeated attempts to get the therapist to tell her what he thought about Jeff's letter, she never truly took a stand because that requires behaving in certain ways over time by dovetailing any single comment with subsequent efforts to develop one's position, clarify it, and so forth, not simply making isolated statements. Therefore, Sharon's feared kind of relationship scenario could not occur because for that to happen her therapist would have had to ignore/neglect her and stayed uninvolved when she really took $a$ stand.

For example, compare the actual transcribed interaction with a hypothetical one in which instead of turns 9 and 11, Sharon stopped repeatedly agreeing with her therapist and instead 
pulled her first few turns together by saying, "I think that the way the letter was written means that Jeff wanted to hurt me. That's important because it would mean that he still cares about me. He wouldn't want to hurt me if he didn't still care. I know you think I should just decide about the letter myself, but I really wish you would tell me if you agree with my interpretation." This bid would link up with Sharon's prior efforts to get the therapist to answer her question, indicate how she felt about Jeff's letter (evidence from the case indicates that the hypothetical turn states what Sharon actually meant by her very unclear reference to "if you wanted to hurt somebody" in turn 11 in the transcript), and clarify what her thoughts were about the therapist's refusal to share his opinion about the letter.

My hypothetical turn is a well-coordinated response. It would have opened up the possibility that her fear could occur. If she had made that response, the therapist might have ignored her by showing no interest in what she just said about Jeff's letter and continued with his efforts to get Sharon to stop asking him for his opinion and start making decisions by herself. But Sharon did not make the hypothetical contribution. Instead, she behaved in a defensive, noncoordinating manner. One upshot of her behavior was that she avoided the possibility that her fear might occur.

Westerman and Prieto (2006, Study 3) found support for this idea that a feared interpersonal event includes how the person in question behaves in addition to how the other person responds. Participants in that experiment reported that they would feel significantly worse if a significant other responded to them in the manner they feared after they acted in a straightforward, nondefensive way than if the other person made the same response after they behaved in a defensive, noncoordinating manner.

There also was another upshot of Sharon's defensive, noncoordinating pattern of interpersonal behavior. Recall that according to Interpersonal Defense Theory, although such patterns include recurring attempts to pursue a wish, they actually work against the wish being realized in the exchange. This is the case for the same reason that defensive patterns work against the fear occurring. Although Sharon's interpersonal pattern included repeated attempts to realize her wish, she also repeatedly derailed her own bids at taking a stand by shifting to agree with the therapist and failing to develop or expand on those individual bids in her subsequent turns. As a result, as I noted above, she did not truly take a stand. Indeed, her pattern of interpersonal behavior made it very difficult for the therapist to even recognize what Sharon's independent viewpoint was and, therefore, very unlikely that he actually would affirm and appreciate her position.

Certainly, Sharon's wished-for response would have been more likely to occur if she had made my hypothetical response instead of the noncoordinating contributions she made in turns 9 and 11 of the exchange. For example, in response to my hypothetical bid, the therapist might have said, "I agree that this is an angry letter and that it may well indicate that Jeff still has feelings for you. I'd like to hear more of your thoughts about this."

\section{TREATMENT IMPLICATIONS}

Interpersonal defense theory has many implications for treatment. In this part of the paper, I first present some of the general implications that follow from the theory. I then show 
how those ideas help us understand why the case was not successful and point to what might have led to a good outcome by considering the transcribed session segment again and what took place in other parts of Sharon's therapy.

\section{General Points}

The most basic implication is that from the vantage point of Interpersonal Defense Theory, the goal of therapy is to help people move from defensive to nondefensive ways of negotiating wish-fear conflicts. Changes of this kind constitute and/or lead to improvement at the level of molar clinical concerns because, as I explained earlier, symptoms and other psychological problems are parts of problematic action patterns (often supports that contribute to maintaining the action patterns) or consequences of those patterns.

Another basic point about treatment implications is that Interpersonal Defense Theory suggests that a wide variety of therapy approaches can lead to successful outcomes (see Westerman, 2018). Perhaps most obviously, this includes therapists' enacted interventions at the level of therapy relationship processes, that is, how the therapist relates to the patient at the process level. In addition, it includes insight-oriented work, behavioral interventions, cognitive approaches, and efforts focusing on emotions. However, the theory does not call for a simple eclecticism. According to Interpersonal Defense Theory, a range of kinds of interventions can be useful if they are guided by the tenets of the theory and a formulation of each case based on the theory.

\section{Important Points for Therapists to Understand about their Patients}

There are many differences between the approach to case formulations based on Interpersonal Defense Theory and other case formulation approaches, notwithstanding the appearance of the familiar terms wish, fear, and defense. These differences make a difference when it comes to what a therapist should do.

These differences lead to three important points for therapists to keep in mind. The first is that although specific concrete hopes and fears (such as getting a new job or losing a job that one likes) are important to consider, therapists should focus primarily on their patients' central interpersonal wishes and fears.

The second point is that therapists should treat patients' central interpersonal wishes as especially important. For one thing, this calls for recognizing that defenses include attempts to pursue wishes in addition to efforts to avoid fears. Indeed, this idea is the basis for the focus on noncoordinating interpersonal patterns. By contrast, many therapists and researchers think about defenses as if they aim solely at avoiding fears. Furthermore, I believe that, more generally (i.e., not just regarding defenses), it is not uncommon for therapists to simply neglect considering what a patient's wish is or to assume that the patient's wish is that the fear will not occur. According to Interpersonal Defense Theory, however, patients' wishes typically are quite different from the simple absence of the fear. For example, Sharon's fear was that when she took a stand, others would neglect or ignore her. Note that others could "not behave" in that feared manner in different ways. If they responded to Sharon with benign guidance, they would not be 
responding in Sharon's feared manner, but they also would not be behaving in the manner she wished-for, which was that others would affirm her and show appreciation for her independent viewpoints.

The third point is that therapists should think about their work in a way that differentiates between a patients' central feared responses and other negative responses that are distinct from their central fear and differentiate between patients' central wished-for responses and other positive responses that are distinct from those wishes. Other approaches to case formulation do not make these distinctions. One upshot of failing to do so is that based on the logic of the selffulfilling prophecy many therapists treat the negative responses a patient often encounters as if responses of that kind are the patient's key fear, whereas according to Interpersonal Defense Theory, a patient's central feared response is different from commonly experienced negative outcomes. Another upshot is that therapists often respond to patients in positive ways that are distinct from the patients' central wished-for responses and believe that they are contributing to a positive alliance by behaving that way (see Westerman \& Muran, 2017). From the standpoint of Interpersonal Defense Theory, responses of this sort fail to provide a patient's wished-for outcome, and they are likely to perpetuate a patient's defensive pattern of interpersonal behavior.

\section{$\underline{\text { Two Types of Interventions }}$}

In BAP, the short-term psychodynamically-oriented treatment approach developed by Pollack et al. (1992) that was employed in Sharon's case, a therapist attempts to promote change by interpreting transference phenomena in the patient's relationships with the therapist and his or her extra-therapy relationships. These insight-oriented efforts are pursued in an active, engaged manner. Therapists persistently keep the focus on patients' maladaptive patterns and often make suggestions, offer comments, and challenge patients about how they are engaging in the sessions. Hence, two of the types of interventions I mentioned earlier played a role in Sharon's case, enacted interventions at the level of therapy relationship processes and insight-oriented work. In what follows, I discuss general implications based on Interpersonal Defense Theory for therapeutic efforts that employ these kinds of interventions.

Implications for Therapy Relationship Processes. Whenever a therapist makes a specific identifiable intervention (e.g., an interpretation) at a given point in a session or simply responds to something the patient just said as the two talk about a topic, the therapist is relating to the patient in some way. The therapist's contributions are interpersonal acts that, using SASB terms, might be described as "showing empathic understanding (114)," or "providing for, nurture (142)," or "ignoring, pretending not there (126)," or "putting down, acting superior (136)," and so forth. The ways in which therapists relate to their patients can work against change or help patients develop new, nondefensive ways of relating to them, which can lead, in turn, to changes in how they engage in other relationships.

This idea about enacted interventions at the relationship level of therapy interactions is one of the main ways Interpersonal Defense Theory incorporates in its treatment implications Stiles's (1988) very important point that in order to be helpful, interventions have to be "responsive" to "client requirements." According to the theory, a therapist should relate to each patient in ways that reflect appreciation of idiographic features identified in the formulation of that case. 
Based on these considerations, Interpersonal Defense Theory leads to two specific implications regarding how therapists should relate to their patients. The first point is that when therapists respond to their patients in a countertransferential manner (i.e., behave in ways that include negative responses that are distinct from a patient's fear and positive responses that are distinct from a patient's wish), they are likely to contribute to maintaining patients' defensive patterns, even though many of those efforts might well be well-intentioned attempts that are positive responses distinct from patients' wishes. This is how interpersonal defense theory explains the fact that, as Wachtel (2008) put it, therapists frequently become "unwitting accomplices" in their patients' problematic ways of relating to them.

Patients' defensive interpersonal patterns pull for countertransference responses, but therapists do not have to behave in that manner (although it no doubt is impossible to completely avoid becoming an "accomplice" at some points when working with a patient). In particular, the second point about how therapists relate to their patients is that according to Interpersonal Defense Theory, therapists can promote change by responding to their patients in ways that realize patients' wished-for outcomes and encourage patients to continue to pursue their wishes. When exchanges of this sort occur, they provide corrective emotional experiences for patients. These experiences make it more likely that they will continue to pursue their wishes in the therapy relationship and possibly in their other relationships as well.

This is not to say that therapists should respond in the manner a patient wishes no matter how the patient behaves. In fact, it is only possible for a therapist to realize a patient's wish when the patient pursues the wish, because interpersonal wishes refer to that sequence of patient and therapist bids, not just the therapist's response. However, when patients relate to their therapists in defensive, noncoordinating ways, they do not provide obvious opportunities for these helpful types of interactions because they do not pursue their wishes in a straightforward manner. Nevertheless, in such situations, therapists do not have to hold off responding in the wished-for manner. Rather, at many moments in therapy it is possible to respond to the part of a patient's defensive pattern that pursues the wish, although recognizing that part may well be difficult because defensive patterns hide and repeatedly derail patients' efforts to pursue their wishes.

A theory-building case study by Westerman and de Roten (2017) illustrates some of the preceding points. That study examined patient and therapist contributions to therapeutic exchange in two episodes each of which involved a session including an alliance rupture followed by a session in which there was partial resolution of the rupture, followed by a session in which there was successful resolution of the rupture.

Therapist behavior in rupture sessions was characterized by negative responses distinct from the patient's fear and positive responses distinct from the patient's wish. The patient was mainly noncoordinating in those sessions. Resolution sessions, on the other hand, were characterized by therapist turns that realized the patient's wish and encouraged the patient to pursue her wish and by mainly coordinating behavior by the patient. Therapist and patient both engaged in the partial resolution sessions in ways that were roughly halfway between how they behaved in the rupture and resolution sessions. In addition, the temporal patterning of therapist and patient behaviors in the sessions examined suggested that therapist behavior played a causal role, influencing whether the patient behaved in a coordinating or noncoordinating manner. 
Implications for Insight-Oriented Work. Although Interpersonal Defense Theory focuses on interpersonal action patterns, it does not point away from therapeutic work aimed at helping patients arrive at new understandings about themselves, other people, and their lives in general.

Certain kinds of insight-oriented efforts can help patients shift to nondefensive ways of relating to others.

Most notably, insight-oriented interventions can promote change when they aim at helping a patient identify and understand his or her central interpersonal wish. Recall, however, that I suggested earlier that patients' wishes often receive little attention in favor of a focus on their fears. I also suggested that when therapists inquire about wishes, they frequently explore such goals as a patient's career hopes, rather than interpersonal wishes, and that sometimes insofar as therapists' insight-oriented efforts concern interpersonal wishes, they often focus on what patients do not want to happen, e.g., to not be rejected (SASB 121), or to not be blamed (135) or put down (136). According to Interpersonal Defense Theory, effective insight-oriented efforts regarding patients' wishes focus on interpersonal wishes that are not simply the absence of feared interpersonal responses.

They also include another feature. They help a patient understand that his or her wish does not only concern other people's responses, but that it involves a relationship in which the other person responds in the wished-for manner when the patient behaves a certain way. This aspect of interpersonal wishes is important because it highlights that patients have to participate in their relationships in certain ways to realize their wishes.

The case study by Westerman and de Roten (2017), which I referred to above, illustrates these points. In that good outcome case, the therapist's bids helped the patient arrive at recognizing and understanding her central interpersonal wish. The insights she arrived at included appreciating that her wish involved how she engaged in her relationships as well as her hoped-for responses by others.

According to Interpersonal Defense Theory, insight-oriented efforts regarding a patient's fear can be useful, but they are not as likely to promote change as insight-oriented work related to the patient's wish. The reason that helping patients gain insight about their fears is less likely to be effective is that it does not offer a positive reason for shifting away from defensive behavior patterns. Even if a patient comes to recognize that he or she is most afraid of a particular kind of interpersonal event in which he or she pursues the wish and the other person responds in a particular dreaded way, why shouldn't he or she continue to act in ways aimed at avoiding exchanges of that sort?

Many insight-oriented interventions about patients' defensive interpersonal patterns have limited effectiveness because they treat defenses as if they solely aim at avoiding fears. When that is the case, they also leave unanswered the question "Why should I change how I behave?" On the other hand, insight-oriented efforts regarding defenses can contribute to successful treatment outcomes when they help patients understand that their defensive patterns include attempts to pursue wishes as well as efforts to avoid fears, but those patterns actually work against realizing those wishes. 
Another point concerns the interplay between insight-oriented efforts and therapy relationship processes. When therapists relate to their patients in ways that promote nondefensive, coordinating patient behavior (as described in the previous subsection), this facilitates productive insight-oriented work. The reason for this is that when patients coordinate their contributions to therapy interactions with their therapists' contributions and their own prior bids, topics of discussion can be clearly established and there can be forward movement in discussions about those topics.

The theory-building case study by Westerman and de Roten (2017) and another theorybuilding case study by Westerman and Muran (2017) found support for this claim that therapist bids which promote coordination by realizing patients' interpersonal wishes in patient-therapist interactions result in better topic establishment and forward movement. In addition, processoutcome studies found that the extent to which patients behaved in a coordinating manner was significantly related to outcome (Hartmann, 2001; Westerman, Foote, \& Winston, 1995; Westerman, Frankel, Tanaka, \& Kahn, 1987). The magnitudes of the associations found were large, accounting for considerably more variance in outcome than relationships that have been found between the alliance and outcome (see Westerman, 2018, p. 313).

\section{Implications for Sharon's Case}

How do the therapist's efforts in Sharon's case compare to these ideas about effective therapeutic work based on interpersonal defense theory? Unfortunately, the therapist's contributions in this poor outcome case uniformly fell short of what the theory recommends regarding both enacted interventions at the level of therapy relationship processes and insightoriented work.

\section{The Therapist's Bids as Interpersonal Acts in the Transcribed Segment}

To begin with, consider the therapist's bids in the transcript from session 11 as enacted relationship events. In turn 2, the therapist responds to Sharon's request for his opinion by saying that his opinion is not important. Turn 2 is an example of the SASB code "block, intrude" (137), which is a specific type of hostile control (see Figure 1). As such, the turn is countertransferential because it is a negative response distinct from Sharon's feared response of being ignored and neglected $(125,126)$. The hostile controlling nature of the therapist's behavior appears more clearly in turn 4 because the therapist continues along the same vein in that turn with another blocking bid even though Sharon had just interjected (turn 3 ) that in her view his opinion is important.

In turn 6, the therapist tries to initiate a new topic by commenting that Sharon finds it hard to make decisions. This turn is described in the SASB model as "sensible analysis" (144), a specific kind of benign guidance or management. In Sharon's case, it is countertransferential because it is a positive response distinct from her wish of being affirmed and appreciated for her independent viewpoint $(118,117,116)$. The therapist's next turns $(12,14,16$, and 18) offer additional sensible analysis. The therapist puts forward an explanation for Sharon's difficulty with decision making. He suggests that Sharon stays confused to "avoid upsetting topics." During this part of the exchange, Sharon goes along with the therapist (turns 15 and 17). 
However, in turn 19, Sharon shifts away from the therapist's viewpoint by going back to her concerns about what Jeff meant by the letter he wrote to her and moving away from the therapist's focus on her, specifically, on why she stays confused. In response (turn 20), the therapist interrupts Sharon and presses on with his point of view. In that turn, he adds to his prior comments the idea that Sharon's stays confused to avoid "feeling pain." This turn is both an instance of sensible analysis (144), because it is another attempt to help Sharon understand herself, and an example of "block, intrude" (137) because the therapist is cutting off Sharon's comments in turn 19 with an interruption that is an attempt to keep Sharon in line, that is, to keep her moving along the therapist's line. When Sharon then persists with trying to shift the focus to Jeff's letter, the therapist interrupts her twice (turns 22 and 24) and offers a clearly hostile controlling bid (turn 24) aimed at forcing Sharon to be responsive to what he thinks they should be considering. Turn 24 can be described in SASB terms as "accuse, blame (135), "put down, act superior (136), "block, intrude," (137) and "enforce conformity” (138).

Note that the therapist's behavior was consistent with the full set of tenets about feedforward effects in Interpersonal Defense Theory. When I previously considered the transcript early in the paper, I pointed out multiple examples of Sharon's defensive, noncoordinating behavior. I also explained that how such behavior on Sharon's part made it very unlikely that the therapist would relate to her in ways that were instances of her central interpersonal wished-for or feared responses. The examination of the transcript I just presented shows that there were no examples of those responses by the therapist. As predicted by the theory coupled with the case formulation, the therapist did not respond in Sharon's feared manner. He by no means ignored her, but rather was very actively engaged in the exchange. In addition, he did not respond to Sharon in the manner she wished-for by affirming her for her independent viewpoints.

Instead, all of the therapist's responses were countertransferential as that concept is understood in Interpersonal Defense Theory, which is to say, they were positive responses distinct from Sharon's wish and/or negative responses distinct from Sharon's fear. Why did Sharon's behavior lead to those responses?

Sharon tried to "cancel out" the parts of her pattern in which she persistently pressed on with her point of view, which was how she pursued her wish. She attempted to cancel out those parts by repeatedly appearing to agree with the therapist. She succeeded in her cancelling out efforts in the sense that she never fully pursued her wish, but she could not undo her attempts to pursue her wish as if those contributions to the exchange never occurred. The overall "package" of repeatedly attempting to pursue the wish and derailing those efforts again and again itself led the therapist to treat her as someone who was difficult to relate to.

At times, he tried to get Sharon (i.e., hostile control, specifically, SASB 135, 136, 137, 138) to be responsive to his point of view and more forthcoming/clear about her own point of view. At other times, he became so frustrated with Sharon that he behaved toward her in an angry, attacking manner $(130,131)$, although this kind of response did not occur in the session segment in the transcript. These two kinds of responses (hostile control and angry attack) are the negative outcomes distinct from Sharon's fear that are part of the case formulation. On other occasions, Sharon's pattern led the therapist to try to help her be more responsive by acting in benevolent managing ways $(144,145,146,147,148)$, although the transcript only includes 
examples of 144 ("sensible analysis"). These are the positive outcomes distinct from Sharon's wish that are also part of her case formulation.

According to another tenet of the theory, countertransference responses like those made by the therapist serve to maintain defensive patterns. In fact, we can imagine that the problematic dyadic exchange in the transcript might go on and on, with Sharon's repeatedly expressing agreement coupled again and again with her recurring efforts to get the therapist to give his opinion about the letter, which would lead the therapist to try to get or help Sharon to be more responsive or prompt the therapist to express frustration with angry attacks, which then would lead Sharon to agree again only to then derail her agreement, and so forth and so on.

In this scenario, the therapist would have felt that he was trying hard to help Sharon and that he was proceeding in a good way (especially when he attempted to provide benign guidance), but he would also feel frustrated because he was not succeeding. For her part, Sharon would be able to repeatedly attempt (albeit defensively) to pursue her wish without her fear occurring. In addition, at least part of the time, the therapist would be trying to help her with his efforts at benign guidance. No doubt, Sharon would not like the therapist's efforts at hostile control or his angry attacks, but those parts of the exchange would not be as upsetting to her as being ignored and neglected.

On the other hand, the therapist could have responded to Sharon differently. For example, he might have responded to S's bid in turn 11 by picking up on the part of that turn in which Sharon seemed to be offering her view that Jeff was trying to hurt her with his letter, even though that part of her bid was hidden by the other parts of the turn in which she asked the therapist for his opinion. Although it would be entirely different from what he actually said following turn 11, the therapist could have responded, "Oh, you're suggesting that Jeff was trying to hurt you. I think you might be right. What do you think about Jeff doing that?"

If the therapist had responded that way (i.e., offering his opinion as requested in response to Sharon's thoughts about the letter and displaying interest in learning about what other related thoughts Sharon might have), he would have realized Sharon's wish of being affirmed and shown appreciation for her independent viewpoint. He would have made a response of the kind she wished-for and linked his response to the part of her turn in which she attempted to pursue her wish. Enacted bids of this sort that realized Sharon's wish might have encouraged her to continue to pursue her wish by putting forward her viewpoint and taking stands on matters of concern to her - and to do so in a nondefensive manner.

\section{$\underline{\text { Insight-Oriented Work in the Transcribed Segment }}$}

From the vantage point of Interpersonal Defense Theory, the therapist's insight-oriented efforts in the transcribed segment also were off the mark. The therapist focused on what Sharon was trying to avoid, not her wish, which as I said earlier is something many therapists do.

I also maintained earlier that a focus on what patients are trying to avoid will have limited usefulness. Furthermore, as I see it, the therapist's ideas about what outcome Sharon was trying to avoid or how she was trying to avoid that outcome were off target. The therapist tried to guide Sharon towards understanding that she stayed confused to avoid "feeling pain." According to 
Interpersonal Defense Theory, there is nothing necessarily wrong with this concern about intrapsychic processes aimed at modulating internal outcomes, but considerations along those lines should be placed in a larger framework that gives primacy to interpersonal phenomena.

In this case, the therapist did not recognize that Sharon's central interpersonal fear was that she would be ignored and neglected when she took a stand and acted independently and, therefore, he was not in a position to help Sharon arrive at insights about that fear. Moreover, because he did not consider Sharon's interpersonal fear, the therapist was off base in a key respect about Sharon's confusion. As I see it, what the therapist referred to as Sharon's "confusion" helped maintain her defensive interpersonal pattern of repeatedly taking a stand while she also repeatedly deferred to and agreed with the other person. The primary thing to recognize about her confusion was that it contributed to successfully avoiding her interpersonal fear of being neglected and ignored - and, in fact, kept others, including the therapist, very engaged with her.

If the therapist had helped Sharon arrive at insights about her fear and defenses along the lines I just suggested, he would have been on target and his insight-oriented efforts might have made some contribution to a good outcome, but this brings me to the most important point about the therapist's insight-oriented efforts in the transcribed segment. The key point is that those efforts did not include any attempt to help Sharon arrive at insights about her central interpersonal wish. As I explained earlier, insight-oriented work is likely to be most useful when it helps patients develop some appreciation and understanding of their wishes. Also, insightoriented efforts regarding defenses are most likely to contribute to change when they help patients realize that their interpersonal defenses work against realizing their wishes. The therapist's efforts differed completely from these suggestions. He did not try to help Sharon arrive at insights about her central wish and he did not help her recognize that her confusion supported interpersonal defenses that worked against realizing that wish.

\section{$\underline{\text { Some Comments about Other Parts of the Therapy }}$}

Unfortunately, the therapist's contributions throughout the therapy continued along the same vein as his contributions in the transcribed segment. Here, I will offer some brief comments about the therapy overall. The interested reader can see Westerman and Muran (2017) for detailed analyses of other parts of the treatment.

With regard to what the therapist's contributions were like when viewed as interpersonal acts in the case overall, his behavior was quite consistent. Throughout the therapy, his responses were almost entirely countertransferential. The balance between benign guidance/management (positive responses distinct from Sharon's wish) on the one hand and hostile and hostile controlling responses (negative responses distinct from Sharon's fear) on the other went up and down to some degree over time, but he almost always behaved in one or the other of these two ways. Most notably, there were very few examples of therapist responses that affirmed Sharon and showed appreciation for her independence or taking stands. I believe that these enacted features of the therapist's behavior in large measure account for why the therapy was unsuccessful. 
The therapist's insight-oriented efforts in the case overall were also quite similar to what we observed in the transcribed segment. He mostly focused on Sharon's attempts to avoid her fears, although it was also the case that he never recognized what her central fear actually was. In addition, none of his efforts were aimed at helping Sharon understand her central interpersonal wish because he never realized what her wish was.

For example, at one point in the treatment the therapist suggested that Sharon behaved the way she did to avoid conflict with others. According to the formulation of the case based on Interpersonal Defense Theory, however, Sharon's behavior actually promoted conflictual relationships with others in which they often behaved in attacking and hostile controlling ways towards her. Sharon's defensive pattern pulled for those responses as a way of avoiding her key fear, which was being ignored, not encountering conflict. In other words, according to the case formulation based on Interpersonal Defense Theory, the therapist's idea about conflict was an example of mistakenly treating a negative response distinct from a patient's fear as the patient's central fear.

Consider another example, which concerned Sharon's wish. Later in the therapy, Sharon told the therapist that she had recently attended a wedding and that, for the first time when she spent a weekend away from home, she refrained from calling her parents or her sister. Not only did the therapist fail to affirm Sharon for taking this step towards independence, he did not even realize that this was a step towards Sharon's central interpersonal wish. In fact, he actually criticized Sharon because during that weekend she had concerns on her mind (her "confusion"). A therapist guided by the interpersonal defense formulation would have affirmed Sharon for the step she took and, quite possibly, used the example of the wedding weekend as part of efforts to help Sharon arrive at insights about her key wish.

\section{SUMMARY AND CONCLUDING COMMENTS}

Interpersonal Defense Theory offers a reconceptualization of defenses that places the primary focus on interpersonal action patterns. The theory also calls for a novel approach to case formulation. For a given case, the theory coupled with a formulation of the case provides a process model of problematic phenomena that leads to a number of implications for treatment.

In this paper, I have attempted to show that the theory helps us understand the case of Sharon. The theory provided a conceptualization of the case that sheds new light on the nature of Sharon's problems. That conceptualization offered an account of what Sharon's problematic interpersonal behavior pattern was like, why she behaved that way, what the effects of her pattern were, and what maintained the pattern. It also provided the basis for (a) a critique of the therapist's efforts to help Sharon change that might well explain why the case resulted in a poor outcome, and (b) suggestions regarding an alternative approach that might have been more effective. The critique and suggestions about an alternative approach included ideas about two kinds of interventions, enacted therapist contributions to therapy relationship processes and insight-oriented work. 


\section{REFERENCES}

Battle, C. C., Imber, S. D., Hoehn-Saric, R., Stone, A. R., Nash, E. R., \& Frank, J. D. (1966). Target complaints as criteria of improvement. American Journal of Psychotherapy, 20, 184-192.

Benjamin, L. S. (1979). Structural analysis of differentiation failure. Psychiatry: Journal for the Study of Interpersonal Processes, 42, 1-23.

Benjamin, L. S. (1987). Use of the SASB Dimensional Model to develop treatment plans for personality disorders. I: Narcissism. Journal of Personality Disorders, 1, 43-70. https://doi.org/10.1521/pedi.1987.1.1.43

Benjamin, L. S., \& Critchfield, K. L. (2010). An interpersonal perspective on therapy alliances and techniques. In J. C. Muran \& J. P. Barber (Eds.), The therapeutic alliance: An evidence-based guide to practice (pp. 123-149). New York: The Guilford Press.

Downey, G., Freitas, A.L., Michaelis, B., \& Khouri, H. (1998). The self-fulfilling prophecy inclose relationships: Rejection sensitivity and rejection by romantic partners. Journal of Personality and Social Psychology, 75, 545-560.

Eells, T. D. (Ed.). (2007). Handbook of psychotherapy case formulation (2 $2^{\text {nd }}$ ed.). New York: Guilford.

Hartmann, H. A. (2001). Clients' contribution to the alliance and the role it plays in outcome. Dissertation Abstracts International: Section B: The Sciences and Engineering, 61, 4406.

Kramer, U. (Ed.). (2019). Case formulation for personality disorders: Tailoring psychotherapy to the individual patient. London: Academic Press.

Muran, J. C., Safran, J. D., Samstag, L. W., \& Winston, A. (2005). Evaluating an alliancefocused treatment for personality disorders. Psychotherapy, 42, 532-545.

Persons, J. B. (1991). Psychotherapy outcome studies do not accurately represent current models of psychotherapy. American Psychologist, 46, 99-106.

Pollack, J., Flegenheimer, W., Kaufman, J., \& Sadow, J. (1992). Brief adaptive psychotherapy.for personality disorders: A treatment manual. San Diego, CA: Social \& Behavioral Documents.

Stiles, W. B. (1988). Psychotherapy process-outcome correlations may be misleading. Psychotherapy, 25, 27-35.

Wachtel, P. L. (2008). Relational theory and the practice of psychotherapy. New York, NY: Guilford.

Wachtel, P. L. (2017). The relationality of everyday life: The unfinished journey of relational psychoanalysis. Psychoanalytic Dialogues, 27, 503-521.

Westerman, M. A. (2018). Interpersonal defense theory: An integration of philosophical considerations, psychoanalytic concepts, and perspectives on interpersonal processes that provides a guide for a wide range of therapeutic interventions. Journal of Psychotherapy Integration, 28, 310-328.

Westerman, M. A. (2019). Case formulation in interpersonal defense theory: A process model of interpersonal phenomena that play key roles in psychopathology and psychotherapy. In U. Kramer (Ed.), Case formulation for personality disorders: Tailoring psychotherapy to the individual client (pp. 315-335). London, United Kingdom: Elsevier.

Westerman, M. A., \& de Roten, Y. (2017). Investigating how interpersonal defense theory can augment understanding of alliance ruptures and resolutions: A theory-building case study. Psychoanalytic Psychology, 34, 13-25. 
Westerman, M. A., Foote, J. P., \& Winston, A. (1995). Change in coordination across phases of psychotherapy and outcome: Two mechanisms for the role played by patients' contribution to the alliance. Journal of Consulting and Clinical Psychology, 63, 672-675. doi: 10.1037/0022-006X.63.4.672

Westerman, M. A., Frankel, A. S., Tanaka, J. S., \& Kahn, J. (1987). Client cooperative interview behavior and outcome in paradoxical and behavioral brief treatment approaches. Journal of Counseling Psychology, 34, 99-102. doi:10.1037/0022-0167.34.1.99

Westerman, M. A., \& Muran, J. C. (2017). Investigating an approach to the alliance based on interpersonal defense theory. Psychotherapy Research, 27, 620-641.

Westerman, M. A., \& Prieto, D. M. (2006). Expectations about the short-term functional role played by defensive behavior in interpersonal interactions. Journal of Research in Personality, 40, 1015-1037. 
Figure 1. Structural Analysis of Social Behavior (SASB). Full Model except figure omits the introject surface and includes only the two interpersonal surfaces. Figure 2 on p. 6, Benjamin, L.S. (1979). Structural analysis of differentiation failure. Psychiatry: Journal for the Study of Interpersonal Processes, 42, 1-23. Reprinted with permission of Guilford Press. 114 Show empathic ic understanding 13 Confirm as OK as is 112 Stroke, soothe, calm 111 Warmly welcome 110 Tender sexuality

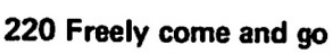

Go own separate way $228 \square 218$ Own identity, standards Defy, do opposite 227 Assert on own Busy with own thing 226 - 1216 "Put cards on the table"

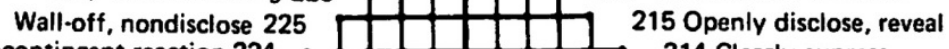

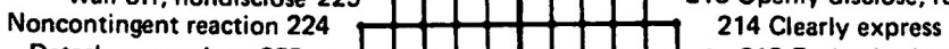

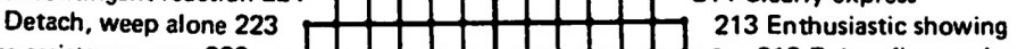

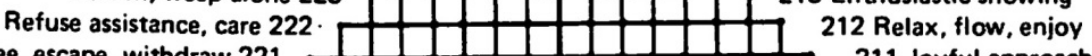
Flee, escape, withdraw 221 w Desperate protest 230

Wary, fearful 231 Sacrifice greatly 232 Whine, defend, justify 233 Uncomprehending agree 234 Appease, scurry 235 Sulk, act put upon 236 Apathetic compliance 237 Follow rules, proper 238 210 Ecstatic response 241 Follow, maintain contact Yield, submit, give in $\mathbf{2 4 0}$ 